Babelyuk V., Dobrovolsky Yu., Korsuns'kyi I., Kuzenko V., Popovych I., Zukow W. The algorithm of the electric stimulator VEB-1 software operation. Journal of Education, Health and Sport. 2020;10(5):403-409. eISSN 2391-8306. DOI http://dx.doi.org/10.12775/JEHS.2020.10.05.042

https://apcz.umk.pl/czasopisma/index.php/JEHS/article/view/JEHS.2020.10.05.042

https://zenodo.org/record/5006751

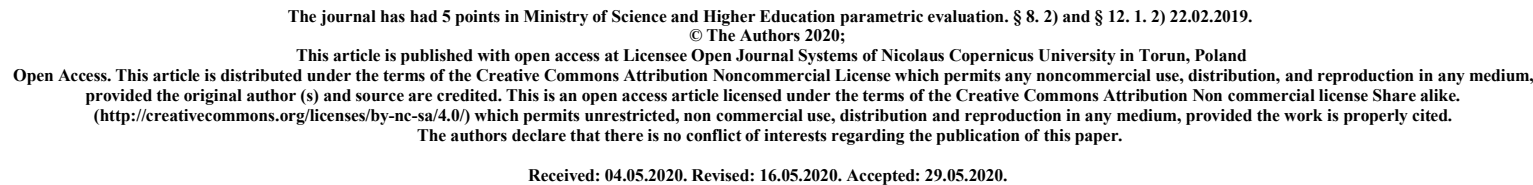

Received: 04.05.2020. Revised: 16.05.2020. Accepted: 29.05.2020.

\title{
THE ALGORITHM OF THE ELECTRIC STIMULATOR VEB-1 SOFTWARE OPERATION
}

\author{
${ }^{1}$ Babelyuk V., ${ }^{2}$ Dobrovolsky Yu., ${ }^{3}$ Korsuns'kyi I., ${ }^{3}$ Kuzenko V., ${ }^{4}$ Popovych I., ${ }^{5}$ Zukow W. \\ ${ }^{1}$ Clinical Sanatorium “Moldova”, Truskavets', Ukraine san.moldova.tr@ukr.net \\ ${ }^{2}$ Yuriy Fedkovych Chernivtsi National University Chernivtsi, Ukraine yuriydrg@ukr.net \\ ${ }^{3}$ Specialized design bureau "PDK", Chernivtsi, Ukraine igkors@ukr.net \\ [4Bohomolets' Institute of Physiology of NAS, Kyïv, Ukraine i.popovych@biph.kiev.ua \\ ${ }^{5}$ Nicolaus Copernicus University, Torun, Poland w.zukow@wp.pl \\ Corresponding Author Walery Zukoww.zukow@wp.pl
}

\begin{abstract}
This thesis demonstrates results of the electric stimulator VEB-1 software operation algorithm development. To increase the device efficiency, the algorithm is composed using the frequency beat method. Our software solutions allowed us to provide the needed precision to maintain the operating frequency of the electric current pulses that penetrate through the human body on the level not less than $0,001 \mathrm{~Hz}$. The software allows the operator to control the electrostimulation process through the screen, where all active processes are displayed.
\end{abstract}

Key words: Algorithm, electric stimulator VEB-1, software, frequency.

\section{Introduction}

One of the topical and sought-after nowadays research directions in medical instrument engineering is the biometric devices for the nervous system electrostimulation development. As known [1-5], electrostimulation is applied to amplify, stimulate or 
rehabilitate the operation of certain organs and systems of the human body, damaged by the disease.

Electrostimulation of the nervous system is conducted by affecting on the organism with small current pulses that imitate the ordinary nervous system's signals. Modern electrostimulation devices generate pulses of rectangular, triangular and flat-topped shapes with variable frequency and duration. To attain the effective stimulation of the weakened organ, it's also needed to ensure the total matching of the frequency generated by the device and the own organ operating frequency. Among the displayed on the market electrostimulators of the muscules, nerves and certain organs, there is a big number of devices, able to maintain the accuracy of the frequency setting on the level of $0,1-0.01 \mathrm{~Hz}[6-$ $12]$.

Whilst, the operating frequencies of the same organs of different people might differ. According to our research $[13,14]$, this diversity can be represented as a certain frequency range, and the deviation from person to person might equal from 0,1 to $0.001 \mathrm{~Hz}$.

The VEB-1 device is developed following the higher mentioned demands of stimulating human organs with the maintained operating frequency precision on the level not less than $0,001 \mathrm{~Hz}$. The device construction was, as well, mentioned before $[13,14]$.

The thesis purpose is to demonstrate the results of the VEB-1 device's software algorithm development.

As we've mentioned before, [14] basically, to increase the efficiency of the impact on the human organism nerve centers of the modulated current, the device uses the frequency beat method $[15,18]$.

\section{The nerve nodes balancing program general algorithm}

In our case, the solution of the task to get the frequency beat effect is to form, by two signal channels, the rectangular shaped pulses with the frequency offset equal to the beat frequency [15].

Mostly the beats occur as a result of the signal pulse phase offset while each new pulse is forming. The phase offset is aliquot to the frequency offset of the above mentioned two channels $f_{1}$ and $f_{2}$. We are interested in the number of phases per one second $\mathbf{N}_{\mathbf{t}}$. One phase here means one frequency beat.

For example:

$$
N_{t}=f_{1}-f_{2},
$$

$f_{1}=4.5 \times 32=144$

$f_{2}=144+4.5=148.5$

$N_{t}=148.5-144=4.5$.

That's how we get 4.5 frequency beats per second.

As it's mentioned in [13], to get the beat with the frequency of i.g. $6 \mathrm{~Hz}$, we form the pulses in two channels: the first channel has the carrier frequency of $30 \mathrm{~Hz}$ and the second $36 \mathrm{~Hz}$. At the same time, the carrier frequency $f_{n}$ is re estimated for each nerve node's frequency range stepwise passing. For the first channel we get the frequency

$$
f_{1}=32 \cdot f_{b},
$$

where 32 is the 32 -nd subharmonic of the beat frequency; and $f_{b}$ - the beat frequency.

The second channel frequency equals:

$$
f_{2}=32 \cdot f_{b}+f_{b},
$$

Consequently, the carrier frequency is always the 32 -nd subharmonic relative to the beat frequency $f_{b}$. 
Considering the formulas 1-3 we get the resulting device operating algorithm, written on $\mathrm{C}++$ programming language.

The algorithm for setting the needed frequency block diagram, formed according to the formulas $1-3$ for the loop $N_{1}$ and $N_{2}$ is displayed on the figure 1 . The rest seven loops are passed by the program in the same way, that is shown on the figure 1 .

Step 1. During first 30 seconds the stimulation is conducted with the $4.5 \mathrm{~Hz}$ frequency of pulses, that lead to the state of tranquillity. The part of code that describes this step is mentioned farther:
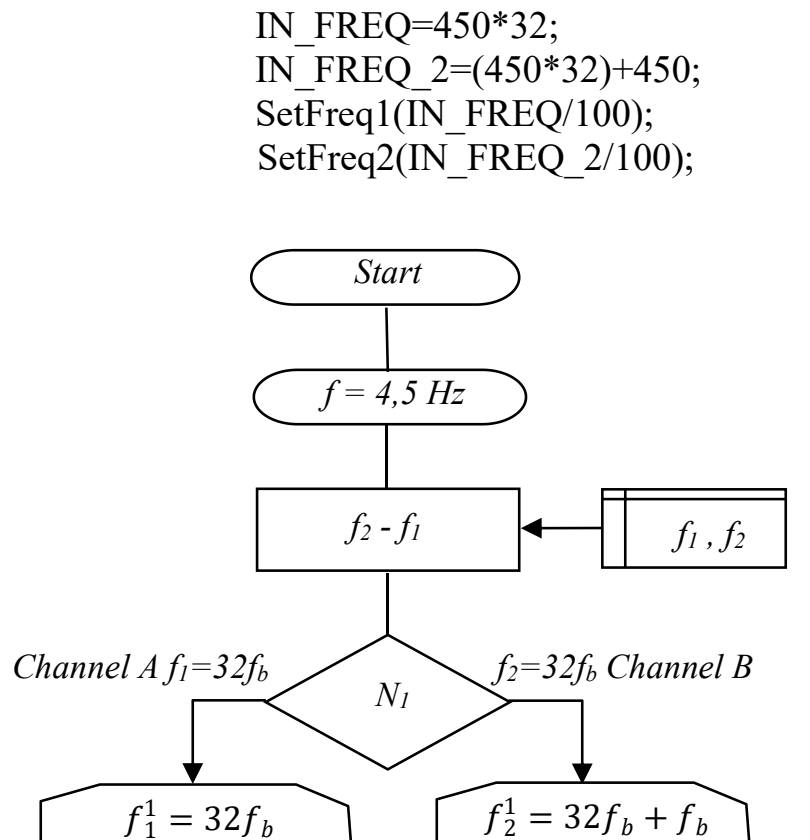
during one minute. The part of code that describes this step is mentioned farther:

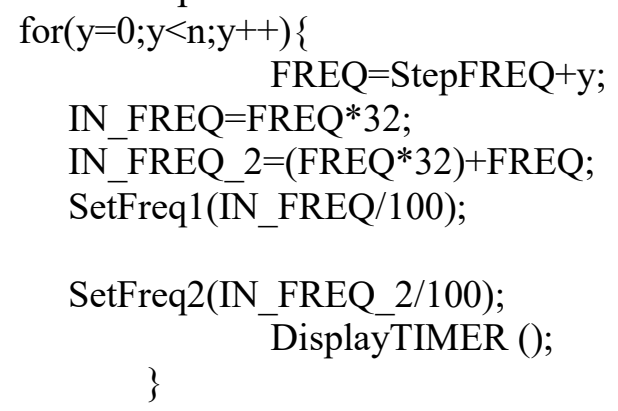

Step 3. $N_{2}$ is the stepwise increasing of the frequency in the second nerve node's range with the step of $0.01 \mathrm{~Hz}$ and the interval of 3 seconds. After reaching the highest frequency of the range, the stimulation with this frequency continues during one minute. The part of code that describes this step is alike to the above mentioned one and to the farther going loops as well.

Step 4. $N_{3}$ - is the stepwise increasing of the frequency in the third nerve node's range with the step of $0.01 \mathrm{~Hz}$ and the interval of 3 seconds. After reaching the highest frequency of the range, the stimulation with this frequency continues during one minute.

Step 5. $N_{4}$ - is the stepwise increasing of the frequency in the fourth nerve node's range with the step of $0.01 \mathrm{~Hz}$ and the interval of 3 seconds. After

Fig. 1. Block diagram of the algorithm for setting the desired frequency for cycle $N_{l}$ and $N_{2}$ 
reaching the highest frequency of the range, the stimulation with this frequency continues during one minute.

Step 6. $N_{5}$ - is the stepwise increasing of the frequency in the fifth nerve node's range with the step of $0.01 \mathrm{~Hz}$ and the interval of 3 seconds. After reaching the highest frequency of the range, the stimulation with this frequency continues during one minute.

Step 7. $N_{6}$ - is the stepwise increasing of the frequency in the sixth nerve node's range with the step of $0.01 \mathrm{~Hz}$ and the interval of 3 seconds. After reaching the highest frequency of the range, the stimulation with this frequency continues during one minute.

Step 8. $N_{7}$ - is the stepwise increasing of the frequency in the seventh nerve node's range with the step of $0.01 \mathrm{~Hz}$ and the interval of 3 seconds. After reaching the highest frequency of the range, the stimulation with this frequency continues during one minute.

Step 9. $N_{8}$ - is the stepwise increasing of the frequency in the eighth nerve node's range with the step of $0.01 \mathrm{~Hz}$ and the interval of 3 seconds. After reaching the highest frequency of the range, the stimulation with this frequency continues during one minute.

Step 10. $N_{9}$ - is the stepwise increasing of the frequency in the ninth nerve node's range with the step of $0.01 \mathrm{~Hz}$ and the interval of 3 seconds. After reaching the highest frequency of the range, the stimulation with this frequency continues during one minute.

While the algorithm is executed, the current values are displayed on the screen (fig. 2) The screen on the picture 2 displays:

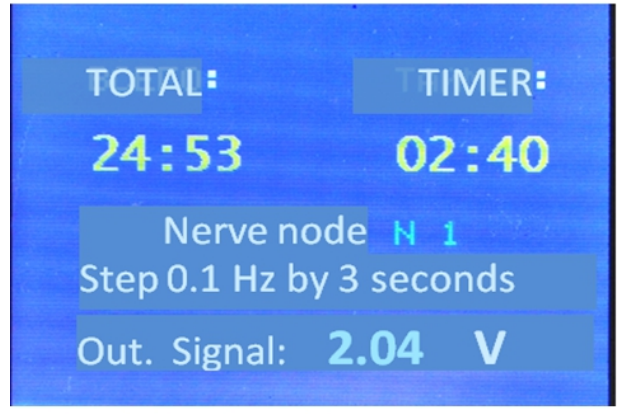

Fig. 2. Display of device operation.
- the total time left to the end of the stimulation, timer of how long the device is on;

- the nerve node's number, that is currently stimulated by the device;

- the frequency change step for each 3 seconds;

- the voltage of the outer signal.

The part of code that describes the information output is shown farther:

ILI9341_COLOR_GREEN, FonScreen, FONT_2X);

SendString("Nerve Nodes ", 40, 50, ILI9341_COLOR_YELLOW, FonScreen, FONT_2X);

sprintf(chr1, "\%d freq. по \%d min.", buf1, buf2);

SendString(chr1, 40, 100, ILI9341_COLOR_WHITE, FonScreen, FONT_2X);

sprintf(chr2, " Time: \%d min.", buf3);

SendString(chr2, 40, 130, ILI9341_COLOR_WHITE, FonScreen, FONT_2X);

sprintf(strbuf, "\%.2f / \%.2f Hz", (float)freq1/100, (float)freq $2 / 100$ );

TM_ILI9341_Puts(x, y, strbuf, \&TM_Font_11x18, ILI9341_COLOR_GREEN, FonScreen);

Particularly, the output of the timers counters, timer 1 - general and timer 2 - the current frequency timer and their precision guarantying are performed by the farther code: void DisplayTIMER (void)

char chrs[10];

int $\min 1$, $\min 2$;

int $\sec 1, \sec 2$;

if $($ Timer $>59)\{\min 1=$ Timer $/ 60 ; \sec 1=$ Timer $-(\min 1 * 60) ;\}$

else $\{\min 1=0 ; \sec 1=$ Timer; $\}$

if $($ TimerFull $>59)\{\min 2=$ TimerFull $/ 60 ; \sec 2=$ TimerFull $-(\min 2 * 60) ;\}$

else $\{\min 2=0 ; \sec 2=$ TimerFull; $\}$

$/$ Format time */

sprintf(chrs, "\%02d:\%02d \%02d:\%02d", min2, sec2, min1, sec1 ); 

FonScreen);

TM_ILI9341_Puts(40,80, chrs, \&TM_Font_16x26,

ILI9341_COLOR_YELLOW,

return;

\}

When we form the first pulse on both channels $\left(f_{1}\right.$ and $\left.f_{2}\right)$ with the phase shift of $0^{\circ}$, we get the absolute zero for the current in the output. (fig. 3).

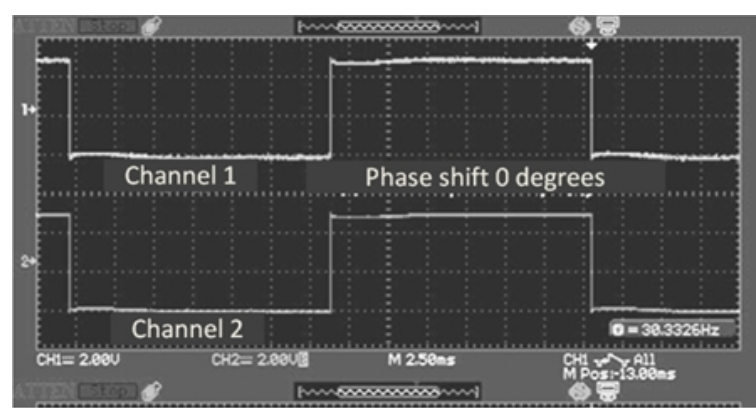

Fig. 3. Oscillogram of the first clock pulse.

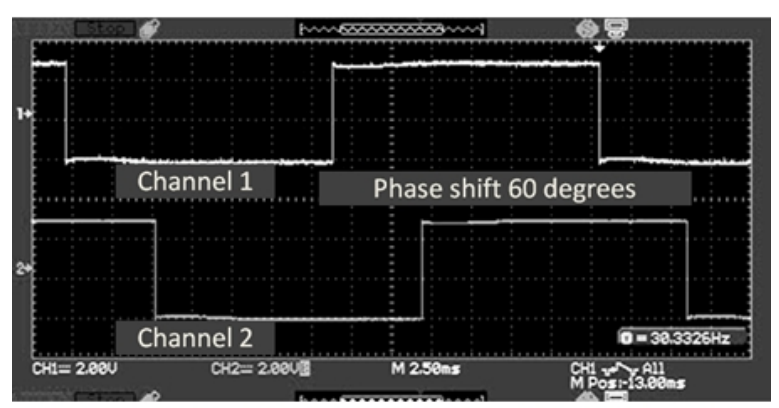
pulse with a frequency difference of $6 \mathrm{~Hz}$ (phase shift $360^{\circ} / 6=60^{\circ}$ ).
Fig. 4. An example of the formation of a second

When we form the second pulse $f_{1}^{2}$, because of the frequency difference in $6 \mathrm{~Hz}$ the phase shift of $360^{\circ} / 6=60^{\circ}$ occurs. On the output, accordingly, we get the pulse, which duty cycle is $100 \% / 6=16.67 \%$. In this case the the phase shift increasing on $60^{\circ}$ accompanies each next clock (fig. 4).

The developed algorithm and the resulting software was tested by the oscillograph ATTEN 1102CAL. The output frequency, generated by the program measuring was conducted with the help of the built in the generator RIGOL DS4162 frequency counter.

The measurements showed, that the frequency maintaining accuracy, used for the stimulating current modulation, is less than $10^{-3} \mathrm{~Hz}$. This allows to consider the minimum variations between the operating frequencies of different patients' nerve nodes.

The device clinical trial results, presented in $[16,17]$ demonstrate the avarage improvement of the measured markers of a person's health state (20 items) after the device stimulation range between $10 \%$ and $15 \%$. At the same time for some certain markers the resulting value have increased on the higher percentage. I.g. the total testosterone increase equals $29 \pm 6 \%$; the number of microbes, absorbed by one phagocyte, have increased on $21 \%$, with the measurement error of $8 \%$.

\section{ACCORDANCE TO ETHICS STANDARDS}

Tests in volunteers are conducted in accordance with positions of Helsinki Declaration 1975, revised and complemented in 2002, and directive of National Committee on ethics of scientific researches. During realization of tests from all participants the informed consent is got and used all measures for providing of anonymity of participants.

\section{Conclusions.}

The comparing analysis of existing electrostimulators demonstrated their disability to provide the maintaining operating frequency pulse of the electric current equaled to $0,001 \mathrm{~Hz}$.

The frequency beat method is the proven most reasonable instrument to reach the high efficiency of the stimulation effect. 
The exploration of the device operating have shown that the current pulses penetration into the human organism is provided with the maintaining operating frequancy accuracy of not less than $0,001 \mathrm{~Hz}$.

\section{References}

[1] Gerard Koel and Pamela E. Houghton, Electrostimulation: Current Status, Strength of Evidence Guidelines, and Meta-Analysis. Adv Wound Care (New Rochelle). 2014 Feb 1; 3(2): 118-126. doi: 10.1089/wound.2013.0448.

[2] Nantawachara Jirakittayakorn Yodchanan Wongsawat Brain Responses to a 6-Hz Binaural Beat: Effects on General Theta Rhythm and Frontal Midline Theta Activity / Front. Neurosci., 28 June 2017. https://doi.org/10.3389/fnins. 2017.00365.

[3] Kern H., Carraro U., Adami N., Biral D., Hofer C., Forstner C., Mödlin M., Vogelauer M., Pond A., Boncompagni S., Paolini C., Mayr W., Protasi F., Zampieri S. Home-based functional electrical stimulation rescues permanently denervated muscles in paraplegic patients with complete lower motor neuron lesion // Neurorehabil Neural Repair. - 2010. - №. 24 (8). - P. 709 -721.

[4] Nathaniel J. Zuk, Laurel H. Carney and Edmund C. Lalor' Preferred Tempo and LowAudio-Frequency Bias Emerge From Simulated Sub-cortical Processing of Sounds With a Musical Beat. 29 May 2018, https://doi.org/10.3389/fnins.2018.00349.

[5] Guyot, M., Simon, T., Ceppo, F. et al. Pancreatic nerve electrostimulation inhibits recentonset autoimmune diabetes. Nat Biotechnol 37, 1446-1451 (2019). https://doi.org/10.1038/s41587-019-0295-8.

[6] Pat. 2164424 RF. Method of low-frequency electromagnetic therapy and a device for its implementation / Konoplev S.P., Konopleva T.P. - 03/27/2001. - Bul. No. 11. (Rus).

[7] Pat. Germany 4238745. A device for generating a magnetic field with a duplicated system and an anti-jamming device / Walter Kaufmann. - 05/19/1994 .

[8] Vasilyeva L.V., Gorkovenko I.A. Low-frequency electromagnetic therapy alternative to antibiotic therapy of ulcerative lesions of gastrointestinal tract // Bulletin of new medical technologies. - 2103. - rel.2, T. XX. - P. 185-187. (Rus).

[9] Device of pulsed electromagnetic therapy // Bulletin of sports innovations. - 2012.- No. 38.- P. 6. (Rus).

[10] Pat. for utility model No. 101365 RF. A device for electromagnetic therapy / Shafov S. K., Soloviev S. V. - 2011.-Byul. No. 2. (Rus).

[11] Pat. Ukraine for useful model No. 49957 Portable device for electrotherapy and stimulation / Turchinov A.N. Volkovinskaya AA — 2010.— Byull. No. 9. (Ukr).

[12] Babeluk N.V., Babeluk V.Y., Dubkova G.I. that in. Modulation of functional systems of practically healthy people in the course of electrostimulation // IX International symposium "Actual problems of biophysical medicine." - 2016. - Ukraine, M. Kiev. - P. 10-11. (Ukr).

[13] Babelyuk VY, Dobrovolskiy YyG, Popovych IL, Korsunskiy IG. Generator for electrotherapy and stimulation oh human nerve centers [in Russian]. Tekhnologiya i Konstruirovaniye v Elektronnoy Apparature. 2017; 1-2: 23-27.

[14] Babelyuk Valeriy Ye, Babelyuk Nazariy V, Popovych Igor L, Dobrovol's'kyi Yuriy G, Korsuns'kyi Igor H, Korolyshyn Tetyana A, Kindzer Bohdan M, Zukow Walery. Influence of the course of electrostimulation by the device "VEB-1" on parameters of electroencephalogramm at practically healthy males. Journal of Education, Health and Sport. 2018; 8(4):195-206. DOI http://dx.doi.org/10.5281/zenodo.1219029.

[15] R. E. D. Bishop. Vibration. Second edition. Cambridge University Press, 1979 p. - 164p.

[16] Babelyuk N.V. The Influence of the Course of Electrostimulation by the Device "VEB1" on Metabolic Parameters of Practically Healthy Men / N.V. Babelyuk, V.Y. 
Babelyuk, V.V. Kikhtan, I.L. Popovych, M.M. Burkovs'Ka, Y.G. Dobrovolskyi, I.H. Korsuns'Kyi, B.M. Kindzer, W. Zukow // Experimental and Clinical Physiology and Biochemistry- 2018. -V 84(4)/ P. 11-17. https://doi.org/10.32388/JA6NS9.

[17] Babelyuk Valeriy Ye. Perspectives on the use of electrostimulation with the device "VEB" ${ }^{\circledR}$ in the management of disorders related to COVID-19 / Valeriy Ye. Babelyuk, Igor L. Popovych, Nazariy V. Babelyuk, Tetyana A. Korolyshyn, Galyna I. Dubkova, Marta M. Kovbasnyuk, Victor Y. Hubyts'kyi, Volodymyr V. Kikhtan, Vira Y. Musiyenko, Iryna G. Kyrylenko, Yuriy G. Dobrovolsky, Igor H. Korsunskyi, Radosław Muszkieta, Walery Zukow, Anatoliy I. Gozhenko // Balneo Research Journal. Vol.11, No.3, September 2020 p: 328-343. DOI: http://dx.doi.org/10.12680/balneo.2020.361

[18] Gozhenko A., Biryukov V., Muszkieta R., Zukow, W. Physiological basis of human longevity: the concept of a cascade of human aging mechanism. Collegium antropologicum, 2018; 42(2): 139-146. 